\title{
O estudo operatório da argumentação
}

The operative study of argumentation

\author{
Albano Dalla PRIA (UNEMAT) \\ adallapria@gmail.com
}

Fátima Graziele de SOUZA (UNEMAT) grazi251@hotmail.com

\section{0}

PRIA, Albano Dalla; SOUZA, Fátima Graziele de. $O$ estudo operatório da argumentação. Entrepalavras, Fortaleza, v. 7, p. 170-187, ago./dez. 2017.

Resumo: Nosso objetivo, neste trabalho, é reorientar o estudo da argumentação para um ângulo perceptivo que difere do projeto teórico de Ducrot e seguidores. Especificamente, defendemos que a argumentação seja apreendida não como o ato de um sujeito que coloca em funcionamento la langue, mas como uma atividade constitutiva do funcionamento das línguas enquanto sistemas simbólicos de representação da significação construída pelos sujeitos em situação particular de diálogo. Nosso objetivo foi sustentado pela análise operatória de dois marcadores da língua francesa: peu e un peu. O trabalho teórico-metodológico foi fundamentado pela articulação da linguagem com as línguas naturais, conforme Culioli (1990, 1999a, 1999b). Concluímos que a presença do outro visa, do ponto de vista argumentativo, ratificar o ponto de vista do locutor no enunciado, e, do ponto de vista operatório, equilibrar as assimetrias experienciais (pontos de vista) e linguísticas (arranjos léxicogramaticais) entre sujeitos.

Palavras-chave: Argumentação. 
Abstract: This paper aims to guide the study of argumentation to a point of view different from that of Ducrot and followers. Specifically, we claim argumentation be apprehended, not as the act of someone to put la langue functioning, but as a constitutive activity of the functioning of languages as symbolic systems of representation of meaning constructed by subjects in situations of dialogue. Our objective was supported by the operative analysis of two well-known French markers: peu and un peu. Our methodology was based on the articulation of language with natural languages, according to Culioli (1990, 1999a, 1999b). Our main conclusion is that the presence of alterity in utterance is: from the argumentative angle, for validating the speaker's viewpoint; from the operative angle, for equilibrating experiential (viewpoints) and linguistic (lexical-grammatical patterns) asymmetries between subjects.

Keywords: Argumentation. Operations. Meaning.

\section{Introdução}

Está consolidado, em linguística, o estudo da argumentação sob o ângulo perceptivo do projeto teórico de Oswald Ducrot e seguidores. Desse ponto de vista, a argumentação é muito bem definida como o ato de um certo sujeito que, dotado de intenções de significação, coloca em funcionamento a língua, entendida aqui como sendo la langue de Saussure (1971), dentro de um acontecimento enunciativo.

Nosso objetivo, neste trabalho, é reorientar o estudo da argumentação para outro ângulo perceptivo, especificamente, aquele da articulação da linguagem com as línguas naturais, desenvolvido por Antoine Culioli e seguidores. Propomos que a argumentação seja apreendida não como o ato de um sujeito qualquer que coloca em funcionamento la langue, mas como uma atividade constitutiva do funcionamento das línguas, enquanto sistemas simbólicos de representação suscetíveis à variação em toda a sua profundidade, no tempo, no espaço, de uma cultura a outra, entre falantes e intrafalantes, como resultado da prática de construção de significação dos sujeitos em situação particular de diálogo.

A fim de subsidiar o cotejo dos dois pontos de vista teóricos, retomamos de Anscombre e Ducrot (1988, p. 197) sua célebre análise dos marcadores peu e un peu da língua francesa, e investimos na análise operatória desses marcadores. Os resultados desse investimento, oferecemos ao leitor deste trabalho.

Entre esta Introdução e a Conclusão, outras duas seções compõem este trabalho. Na seção que segue à Introdução, oferecemos ao leitor uma síntese do projeto teórico de Ducrot, nomeadamente, da 
v. 7 (2)

$170-187$ ago/dez 2017

versão Standard da Teoria da Argumentação na Língua1, doravante TAL. Em razão da sua consolidação, a TAL é o ponto referencial em relação ao qual situamos a reorientação que estamos propondo neste trabalho. Por ter subsidiado os objetivos deste trabalho, na seção que antecede à Conclusão, oferecemos ao leitor uma síntese mais extensa do projeto teórico de Culioli, que tem sido mais divulgado, no Brasil, como Teoria das Operações Predicativas e Enunciativas, doravante TOPE.

\section{A argumentação na língua}

Somente na década de 1970 o caráter argumentativo observado na superfície das línguas passa a ser contemplado por uma teoria específica, desenvolvida pelos linguistas Oswald Ducrot e Jean-Claude Anscombre. Até então, questões argumentativas restringiam-se ao domínio da retórica. Portanto, esses linguistas operam o deslocamento de questões da retórica para o campo da semântica linguística.

Na esteira do ponto de vista saussureano de que a compreensão do sentido dos enunciados prescinde do mundo fenomenológico, os dois linguistas concluíram pela inscrição da argumentação no funcionamento da língua, entendida aqui como sendo la langue de Saussure (1971). Com efeito, ratificam o projeto teórico de Saussure, que dispensa a relação de denotação (palavras-objetos) em favor de relações de sentido internas à langue. Desse ponto de vista, entende-se a significação como o resultado do funcionamento da langue nas formas de superfície das línguas. Ademais, aquilo que compreendemos da superfície das línguas como argumento e conclusão toma o lugar de marcas da alteridade enunciativa entre figuras da linguagem, tais como o locutor e o alocutário.

Por esse viés, o enunciado está relacionado ao acontecimento histórico: a existência do que se fala (alguma coisa), sem qualquer existência antes e depois de se falar. A enunciação, desse ponto de vista, se confunde com o momento do dizer. Enquanto acontecimento, o enunciado é da ordem do irrepetível, do único. São determinados a data e o lugar de sua inscrição.

Assim,

[...] a realização de um enunciado é de fato um acontecimento histórico: é dado existência a alguma coisa que não existia antes de se falar e que não existirá mais depois. É esta aparição momentânea que chamo de enunciação (DUCROT, 1987, p.168).

1 Sua formulação consta da obra L'argumentation dans la langue, de Jean-Claude Anscombre e Oswald Ducrot, publicada, originalmente, na Bélgica, em 1983. 
Sob o conceito de enunciação em tela, são compreendidas as várias possibilidades de realização de uma determinada estrutura frasal. Os sentidos são construídos pelos termos do sistema linguístico, colocados em relação num mesmo domínio semântico. Na esteira dessas conceituações, Ducrot (1980, p.11) afirma que a frase "fornece instruções que permitem descobrir, numa situação de enunciação particular, aquilo a que se referem os seus enunciados". Em suma, o programa de trabalho da TAL é este: a argumentação está na língua e as frases, por sua vez, são argumentativas. A interpretação dos enunciados ocorreria a partir do funcionamento de certas formas das línguas que, em sua gênese, conteriam instruções argumentativas sobre o funcionamento da langue, orientadas para a continuação e o encadeamento dos enunciados.

A noção de direcionamento argumentativo é introduzida, nesse ponto da teoria, visando a eficácia argumentativa, entendida como sendo as leis e os limites de funcionamento da langue colocados pelo locutor na enunciação construída. Nesse processo, delimita-se a imagem do outro (alocutário) como a do ser inerte, mudo. A existência da alteridade é proporcional à ratificação do ponto de vista do locutor no enunciado. O outro só existe enquanto reiteração do mesmo. A significação avança na direção da instrução; está orientada para a ratificação de parâmetros e de funções previsíveis. Sobre o labirinto das significações possíveis, prevalece a projeção de um caminho determinado, linear.

Nessa direção, postula-se a existência de certos morfemas, denominados "operadores argumentativos", para ligar os segmentos (sintaxe) que os enunciados comportam e determinar uma dada direção de argumentação-significação (semântica). Desse ponto de vista, as unidades estão vocacionadas a pertencer a uma determinada classe (nomes, verbos, adjetivos, operadores argumentativos etc.). Como procedimento metodológico, a classificação está sustentada pelo enquadramento da unidade numa determinada posição (distribuição) para uma determinada função (relação), e vice-versa. Esse procedimento implica não só um certo grau de homogeneização da variação (alteridade), mas também que certos valores e significados sejam privilegiados na observação das unidades.

Tomemos, por exemplo, os operadores peu e un peu de Anscombre e Ducrot (1988, p. 197). Vejam-se:

(1) Pierre a peu travaillé

(Pedro trabalhou pouco). 
v. 7 (2)

$170-187$

ago/dez

2017
(2) Pierre a un peu travaillé

(Pedro trabalhou um pouco).

Para os teóricos, (1) e (2) remetem ao mesmo fato empírico: o ato de trabalhar em pequena quantidade. Acrescentam que ambas as frases se implicam mutuamente, culminando no seguinte raciocínio: se Pedro "trabalhou pouco", ao menos "um pouco" ele trabalhou. Embora entendam que aquilo que se enuncia em (1) remete a (2) e que o que se enuncia em (2) implica (1), acrescentam que são distintas as intenções argumentativas de (1) e (2).

Se, num dado contexto social, o trabalho for caminho privilegiado para a ascensão moral e econômica, o interlocutor pode vir a concluir:

(1a) Pedro vai fracassar

(2a) Pedro possivelmente terá sucesso.

Essas conclusões são sustentadas por um certo ponto de vista sobre o sucesso e o fracasso, num certo tipo de cultura e de sociedade. A sua problematização foge ao domínio deste trabalho. No entanto, é do ponto de vista que opõe o sucesso ao fracasso, e vice-versa, que são feitas diferenciações argumentativas entre os operadores peu e un peu, tais como:

(1b) Pedro não tem trabalhado

(2b) Pedro tem trabalhado.

O operador mas explicita essas diferenciações em (3):

(3) Pedro trabalhou pouco, mas trabalhou um pouco.

Em suma, a força argumentativa consistiria exatamente no conjunto virtual de enunciados depreendidos de uma dada frase, em um discurso. Assim, o locutor apresentaria o argumento X em favor de Y.

Com efeito, buscaria orientar o alocutário a uma dada conclusão. Desse ponto de vista, as (re)orientações argumentativas não são mero "efeito de estilo". Por certo, ao considerar que o primeiro argumento corre o risco de 
não convencer o destinatário, escolhe uma troca do domínio argumentativo (VOGÜE; PAILLARD, 2011, p.135).

Parece-nos que, nesse ponto, a teoria concede certa autonomia ao alocutário, que pode vir a escapar do domínio do locutor. As adaptações do "dono do enunciado" e sua busca por antecipar os movimentos do interlocutor visam à eficácia argumentativa. A neutralidade está ausente do funcionamento argumentativo da linguagem. Porque aponta para uma dada determinação, todo uso é argumentativo. A intenção é determinada; a orientação argumentativa é determinada. Assim se pronuncia Ducrot: "um enunciado argumentativo apresenta sua enunciação como levando a admitir tal ou tal conclusão" (DUCROT, 1987, p. 174). Desse ponto de vista, a conclusão não é algo a que se chega a partir de um argumento, mas é aquilo que está contido no sentido do próprio argumento. Em outros termos, o sentido dos enunciados é construído pela interdependência semântica dos termos relacionados.

Parece-nos, ainda, que o controle sobre aquilo que o outro (alteridade) pode ou deve concluir torna-se constitutivo do enunciado em alguma medida. Em última instância, é a presença do outro no enunciado que passa a ser controlada. No jogo intersubjetivo subjacente, é inferida/imaginada a reação do outro diante do enunciado. Embora a ideia que se faz do outro seja constitutiva dos direcionamentos argumentativos, esse fundo movediço e subjetivo de pontos de vista variáveis não tem visibilidade na TAL. Teorizar o espaço da alteridade em profundidade recolocaria o problema da variação, excluído da langue por Saussure (1971).

Com efeito, fica a intuição de que o outro apresenta-se como transparente ao locutor, como uma totalidade previsível. No entanto, à medida que o outro se mostra ativo, porque questiona e coloca imprevisibilidades, o locutor reorienta suas "estratégias", busca (re) equilibrar seus valores. Como um tributo ao conceito de langue, esse espaço da diferença, da variação, escapa à TAL. Desse ponto de vista, só resta ao outro existir na enunciação enquanto se torna irredutível ao projeto enunciativo do locutor, orientado à exclusão, à submissão, à rendição do outro, e assim por diante (VOGÜÉ; PAILLARD, 2011, p. 136).

\section{A argumentação na articulação da linguagem com as línguas naturais}

A linguagem foi definida pelo linguista francês Antonie Culioli, proponente da TOPE, como a atividade de representação, referenciação 
e regulação (CULIOLI, 1990, 1999a, 1999b). Sob esse ponto de vista, entende-se que a significação seja um construto da articulação da linguagem com as línguas naturais.

Nessa teoria, a argumentação não tem a visibilidade que lhe dá a TAL. O modo como a TOPE define a linguagem não nos permite pinçar a argumentação como o funcionamento da langue, dado que esta se define como autônoma quanto aos processos de construção da significação. A argumentação enquanto atividade constitutiva do funcionamento das línguas, definidas como sistemas simbólicos de representação de significação construída pelos sujeitos em situação particular de diálogo, está diluída entre outras categorias da linguagem, tais como a

\section{determinação, a modalidade e o aspecto.}

Fundamentada pelo funcionamento da atividade de linguagem, a argumentação será entendida, não como objeto homogêneo ou uma categoria (de língua) construída, mas como um objeto cujo valor é um construto central da atividade de linguagem. A intenção de produzir significação é constitutiva da atividade de linguagem, e não algo que se acopla à langue. Os sujeitos estimam suas representações em relação àquelas que acreditam (conscientemente ou não) ser a do outro. Para tanto, cada sujeito recorre às suas experiências com o mundo psicofísico e cultural, constrói representações e lhes dá forma, num gesto (mental) de percepção ou de categorização do mundo (o linguístico e o extralinguístico). No entanto, esse processo implica adaptação (assimilação e acomodação) às categorizações construídas pelo outro.

Desse ponto de vista, o outro é constitutivo da prática de construção da significação em situações particulares de enunciação. Enquanto atividade subjetiva, a construção de representação cognitiva é anterior à construção linguística ou à representação formalizada e, por essa razão, foge ao domínio do linguista. Ao teorizar os arranjos léxico-gramaticais de uma língua dada enquanto vestígios ou marcas de operações, a linguística culioliana torna possível o acesso do linguista à atividade cognitiva, ainda que se trate de um acesso mediado pelas línguas.

É constitutiva da atividade de referenciação a possibilidade de referir num espaço homogêneo. Para tanto, o sujeito tem de construir coordenadas enunciativas que delimitem um tempo-espaço de interlocução e, com efeito, restrinjam os valores referenciais do enunciado. Essa atividade possibilita que sejam estabelecidas relações entre os elementos dos domínios linguístico e extralinguístico. Como 
se trata de uma relação construída dentro de uma topologia, concluise que não temos correspondência total ou termo-a-termo das representações cognitivas com as representações linguísticas. Não se confunda, portanto, o enunciado com o reflexo ou de um estado mental ou do pensamento.

A equilibração é constitutiva dos processos adaptativos em geral e dos processos enunciativos em particular. A existência do enunciado resulta dos ajustamentos entre um esquema formal, denominado léxis, que se antepõe ao enunciado, como possibilidade de representação, e o contexto encaixante, que se sobrepõe à léxis com marcas de asserção. Se, de um lado, as representações caminham numa dada direção, de outro lado, há direções para onde as representações podem ou devem caminhar ${ }^{2}$.

O jogo das regulações intra e intersubjetivas é constitutivo do processo de colocar em forma (prise en forme) da representação. Se, por um lado, o discurso tende a mitigar as assimetrias intra e intersubjetivas que fundamentam o enunciado, por outro lado, as marcas desse processo o constituem. Por isso, o discurso guarda algum grau de imprevisibilidade, de incerteza e de diferença (não-homogeneidade).

Nesse viés, a enunciação não se confunde com a definição que lhe deu Benveniste. Para esse linguista, "a enunciação é este colocar em funcionamento a língua por um ato individual de utilização" (BENVENISTE, 2006, p. 82). Para Pria (2013),

decorre dessa definição [de Benveniste] que a enunciação deve ser entendida como um conjunto de parâmetros externos ao enunciado e à própria atividade de linguagem. Instaurase o paradoxo: se a enunciação compreende um conjunto de fatores externos ao enunciado e, se o enunciado é produto da enunciação, a enunciação é produto do que? (PRIA, 2013, p. 40).

Os fundamentos epistemológicos da enunciação não são os mesmos para Benveniste e Culioli. Apropriamo-nos das palavras de Pria (2013) para afirmar que Benveniste:

entende a enunciação como a maneira pela qual um sujeito se enuncia (o ato de alguém). Na esteira dessa compreensão, o enunciado será entendido como o produto da enunciação do sujeito (PRIA, 2013, p. 41).

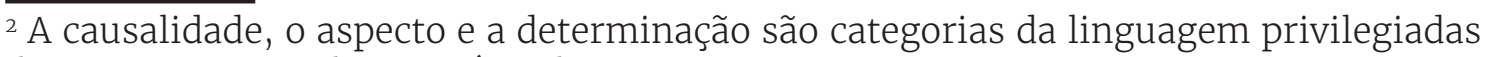
dos ajustamentos da trajetória da representação. 
v. 7 (2) $170-187$ ago/dez 2017

Novamente nos servimos de Pria (2013) para afirmar que Culioli "entende a enunciação como o processo de constituição de um objeto - o enunciado - isto é, a maneira pela qual um enunciado se enuncia. Nesse caso, o enunciado será entendido como o agenciamento de vestígios das operações realizadas na sua construção" (PRIA, 2013, p. 41).

É de natureza distinta a atividade de linguagem para cada um dos dois linguistas franceses. Benveniste entende por atividade de linguagem a prática de operacionalização da langue ("colocar em funcionamento a língua"). Para Culioli, a atividade de linguagem é entendida como a prática de construção de significação em situações particulares. Na esteira de Culioli, Pria (2013) conclui que

a enunciação [não] seja compreendida meramente como um acontecimento singular real em que um enunciado é proferido em uma situação de interlocução. Esse acontecimento é parte de um processo mais amplo que aciona um conjunto de parâmetros abstratos internos à atividade de linguagem (PRIA, 2013, p. 41).

São constitutivos do enunciado os parâmetros referidos por Pria (2013). Sustenta essa afirmação a teorização da ocorrência material do enunciado como o agenciamento de marcas de operações enunciativas subjacentes à superfície textual (CULIOLI, 1978). Com efeito, somos advertidos de que

o enunciado não é apenas uma simples ocorrência material, é também um construto teórico que se pode definir como um agenciamento de marcadores (isto é, de traços de operações), localizado em relação a um sistema complexo de coordenadas enunciativas. O primeiro enunciador (locutor) constrói o enunciado, isto é, determina um agenciamento regulado de marcadores, de modo que o co-enunciador (interlocutor) ajuste seu sistema de determinação, em favor do enunciado (dentre outros índices, e reconstrua através dos traços do texto as operações a que remetem (CULIOLI, 1978, p. 486)33.

A passagem do nível das representações mentais ou cognitivas para o nível das representações referenciais ou linguísticas implica a construção de um espaço de ajustamentos e desvios, distanciamentos e aproximações de representações intra e intersubjetivas. Desse ponto de

\footnotetext{
3 L'énoncé n'est pas une simple occurrence matérielle, mais est aussi un construit théorique, que l'on peut définir comme un agencement de marqueurs (c'est-à-dire de traces d'opérations), repéré par rapport à un système complexe de coordonnées énonciatives. Le premier énonciateur (locuteur) construit l'énoncé, c'est-à-direassigne un agencement réglé de marqueurs, de sorte que le coénonciateur (interlocuteur) ajuste son système de repérage, grâce à l'énoncé (entre autres indices) et reconstruit les opérations dont le texte livre la trace (CULIOLI, 1978, p. 486).
} 
vista, não há espaço para classificações ou construtos homogeneizantes como la langue, nem para explicações da produção de significação que reiterem a autonomia da langue em relação à variação experiencial e linguística.

A apreensão das operações da linguagem que estão sustentando a passagem das representações do nível cognitivo ao nível linguístico, e vice-versa, em situações práticas de construção de significação implica que se opere com instrumentos adequados à maleabilidade das representações que são objeto da articulação da linguagem com as línguas naturais e, além disso, que as explicações do funcionamento dinâmico das línguas estejam fundamentadas pela tese da indeterminação da linguagem.

A partir desse ponto do texto, retomaremos os exemplos (1) e (2) e os analisaremos sob o ponto de vista que defendemos junto à TOPE.

(1) Pierre a peu travaillé

(Pedro trabalhou pouco).

(2) Pierre a un peu travaillé

(Pedro trabalhou um pouco).

Os enunciados (1) e (2) resultam da determinação de um evento em processo, de uma representação em curso, em diferentes pontos de sua trajetória. A representação alcança formatação densa da base nominal (Pedro-o trabalhador), com tendência à construção do compacto (o trabalhador), em (1), em razão do fechamento de pontos espaçotemporais de sua trajetória, numa situação dada. A formatação densa (Pedro, e não outro, trabalhou) da base predicativa é alcançada, em (2), com tendência à construção do discreto (Pedro, dentre outros, trabalhou), em razão da abertura de pontos espaço-temporais, numa situação dada.

A tipologia "discreto", "denso" e "compacto" refere o modo do processo4. Esses tipos relacionam a instanciação da noção num espaço topológico à formatação da representação num espaçotempo enunciativo particular. É a noção de aspecto que sustentará o procedimento metodológico e dará espaço à observação do processo operatório de geração de valores e significados. São ponderações entre operações de quantificação (construção da designação) e de qualificação (construção da predicação) que possibilitam a instanciação de noções

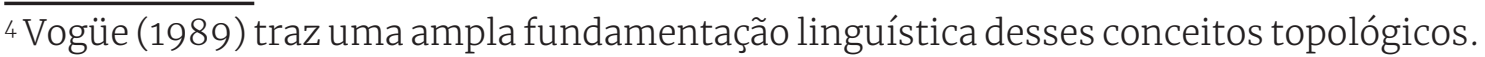


semânticas no espaço particular do diálogo. De um lado, temos a 2017 instanciação das noções semânticas5 (um potencial de significação) num espaço particular de interlocução. De outro lado, a representação passa por ajustamentos sucessivos entre o esquema formal de base (léxis) que se antepõe à apreensão do empírico e o contexto encaixante que se superpõe ao empírico na situação particular. As unidades de significação peu e un peu e o contexto encaixante são igualmente marcas do processo (aspecto) construtor original do enunciado. Por isso, não há como prever aquilo que será o estabilizado e, portanto, "signo". Desse ponto de vista, é sem propósito buscar qualquer correspondência entre o valor de um termo em língua e uma categoria qualquer que o defina na experiência subjetiva. Há vários outros espaços que se abrem ou que se fecham quando se busca uma tal correspondência. Para nós, não basta teorizar tão somente as correspondências, se é que elas existem como tais. Entendemos que também temos de teorizar os espaços que se movimentam, dentro de uma regionalidade de valores e de possibilidades, em razão da busca pela correspondência. A correspondência, assim como qualquer categorização subjetiva da experiência, não antecede a experiência, ela a constitui.

Se, por um lado, o discreto passa a impressão de grau fraco, o compacto passa a impressão de grau forte de determinismo entre as bases nominal Pedro (_ $)$ e predicativa (_ t trabalhar (_ $)^{6}$. Para ir do discreto ao compacto (o trabalhador), é necessário passar pelo denso (Pedro-o trabalhador), que parece elevar o grau de determinismo entre as bases.

Para a construção do compacto, um mesmo sujeito tem de observar, várias vezes, várias ocorrências discretas de predicação, em tempos-espaços variados, variação essa que está indicada por t1, t2, t3, e assim por diante, em (1c). Levado às últimas consequências, o processo de fechamento desses pontos espaço-temporais variados vai resultar na construção de uma classe de predicados (o trabalhador).

(1c) Pedro trabalhou t1, Pedro trabalhou t2, Pedro trabalhou t3 ...

\footnotetext{
${ }_{5}$ Representações abstratas de propriedades físico-culturais apreendidas no interior de uma cultura e de uma língua dadas.

${ }^{6}$ Os intervalos entre parênteses preveem os lugares formais que serão construídos por operações predicativas e enunciativas.
} 
Por um lado, peu situa a noção em relação a uma situação particular, em (1). Por outro lado, marca a distância da ocorrência atual da noção (em construção) em relação ao centro organizador do agregado de ocorrências no interior do domínio nocional. É constitutiva do centro uma ocorrência tipo, isto é, uma ocorrência privilegiada, por ser o exemplar da noção, e um atrator, por exemplo, o alto grau da noção, o trabalhador por excelência, numa classe de indivíduos. Peu é vestígio das operações que buscam equilibrar a desproporção ou a não-conformidade (a diferença ou a distância) entre o alto grau, que se encontra no interior do domínio da noção $\mathbf{P}^{7}$ (Pedro-trabalhador), e a ocorrência atual, em construção, na situação particular. Por isso, ficamos com a intuição de representação não-ainda de Pedro-trabalhador, em (1).

As propriedades $^{8}$ da noção $\mathbf{P}$ se organizam em um espaço topológico, também conhecido como Domínio Nocional, munido de um interior, um exterior e uma região de fronteira. De um lado, o Domínio opera sobre o estável, propriedades físico-culturais definidas e socializadas no interior de uma cultura dada, e, de outro lado, sobre o deformável, modulações do estável que se traduzem, através do contexto encaixante, pela ratificação ou pela reorientação do estável. Levada às últimas consequências, a reorientação pode chegar à dispersão ou à ausência da noção e, portanto, ao vazio da noção.

Com efeito, não só as ocorrências de $p$ (o "verdadeiramente $p$ "), que podem ser encontradas no interior, mas também o complementar da noção (o "verdadeiramente não-p"), no exterior do domínio, são representados pela topologia do Domínio Nocional. Ocorrências de fronteira estão caminhando ou na direção do interior (o quase verdadeiramente-p) ou do exterior (o quase não-p) do domínio.

O compacto passa a intuição de que, no intervalo de espaçotempo de todas as ocorrências de predicação observadas por um mesmo sujeito, o processo trabalhar é uma constante na predicação de alguém que é sempre o mesmo. A intuição de existência de classe (estabilidade fictícia) subjacente à construção do compacto terá de ser confirmada pelas modulações do contexto encaixante, na situação atual.

Ao situar a noção em relação a uma situação particular, em (1), peu restringe a instanciação da base nominal das ocorrências de

\footnotetext{
${ }_{7}$ A noção será representada pela letra $\mathbf{P}$ em negrito e caixa alta. Suas ocorrências, pela letra $p$, em itálico e minúscula.

${ }^{8}$ Seu reconhecimento é resultado de um procedimento metodológico complexo que opera a passagem de ocorrências fenomenológicas a uma ocorrência abstrata.
} 
predicação observadas por um mesmo sujeito (pré-construto) aos

sujeitos que o enunciador acredita serem conhecidos do interlocutor da situação atual. É um pré-construto para o enunciado que o interlocutor também tenha observado ocorrências da predicação de alguém pelo processo trabalhar. Sendo Pedro um desses sujeitos (Falemos de Pedro, dentre outros conhecidos nossos), o enunciador percorrerá o conjunto das ocorrências de predicação do processo trabalhar do pré-construto na busca de identificá-lo.

Se, por um lado, essa operação visa à localização de ocorrências de Pedro em relação às ocorrências de predicação do pré-construto, por outro lado, resulta dessa operação a identificação/diferenciação entre a ocorrência de Pedro da situação atual e os sujeitos das predicações do pré-construto. Assim, peu é vestígio das operações de ajustamento entre a estabilidade subjetiva provisória (o mesmo enquanto outro e o outro enquanto outro mesmo) dada pelos sujeitos das predicações do pré-construto e a estabilidade intersubjetiva em construção na situação atual. Nessa situação, se o enunciador conclui que Pedro, nosso conhecido, trabalhou como sempre, é porque optou por ratificar, através do contexto encaixante, a estabilidade da noção trabalhador, que se encontra no interior do domínio, mesmo quando identificada com Pedro. Esse não é o caso, em (1).

Do ponto de vista intersubjetivo, peu marca, na situação atual, que ainda não se alcançou a saturação da base nominal por um sujeito sempre o mesmo. Logo, peu é uma marca de alteridade que abre caminho a outros sujeitos possíveis. Peu equilibra a instabilidade nocional (a nãoconformidade, a diferença) entre alguém que instancia a base nominal das ocorrências de predicação observadas por um mesmo sujeito no pré-construto (aquelas que o enunciador acredita serem as do seu interlocutor) e o sujeito da representação em construção no intervalo de espaço-tempo da situação atual.

Nessa situação, se o enunciador conclui que Pedro, nosso conhecido, já não trabalha mais como sempre, é porque o alto grau, o trabalhador por excelência, encontra obstáculos à sua instanciação. Em (1), o contexto encaixante joga a noção para a região de fronteira, onde é possível a formatação densa da representação. Com efeito, se por um lado peu equilibra a instabilidade nocional, por outro, reorienta a projeção de estabilidade intersubjetiva que estava colocada como pré-construto para o enunciado. Em suma, a instanciação da noção é compacta e a formatação da representação é densa, em (1). 
Conforme já o dissemos, o discreto passa a impressão de grau fraco de determinismo entre as bases nominal e predicativa. Talvez seja porque, para a determinação do discreto, basta que um mesmo sujeito tenha observado, ao menos uma vez, a ocorrência de predicação de alguém pelo processo trabalhar, e que tenha existido trabalhador pelo menos nesse intervalo de espaço-tempo determinado. Contudo, para ir do compacto ao discreto, se faz necessária a passagem pelo denso, que parece diminuir o determinismo entre as bases.

O processo de abertura de pontos espaço-temporais variados vai resultar na construção de estados resultantes (o trabalho) ou do descontínuo enumerável. Sendo a projeção de existência de trabalhador uma estabilidade provisória ou fictícia para a construção do discreto, ela terá de ser confirmada em situações práticas de construção de significação pelas modulações do contexto encaixante.

Será um obstáculo à instanciação discreta da noção, numa situação enunciativa dada, o sujeito que, tendo instanciado a base nominal, não puder ser chamado de "trabalhador", se esse sujeito não for um predicável de trabalhar, no pré-construto. Como bem sabemos, o trabalhador se determina no intervalo de espaço-tempo determinado pelo processo trabalhar. É com a projeção dessa determinação que o discreto joga.

Será chamado de "trabalhador" o sujeito que, através do processo trabalhar, tiver recebido a propriedade ser trabalhador. Portanto, a determinação da identidade do sujeito (trabalhador) não prescinde do processo trabalhar. É uma estabilidade provisória9 ${ }^{9}$ a projeção de existência de trabalhador para o discreto. Quer dizer que será chamado provisoriamente "trabalhador" o sujeito que vier a instanciar a base nominal até que lhe seja predicado o processo trabalhar numa situação enunciativa atual. Em situações práticas de construção de significação, são as modulações do contexto encaixante que poderão confirmar a relação predicativa subjacente e a existência de trabalhador que ela projeta na construção do discreto.

Por umlado, unpeu situa a noção em relação auma situação particular, em (2). Por outro lado, é marca da não confirmação, na situação atual, da projeção de existência de trabalhador do pré-construto. Un peu é marca da alteridade considerada e suprimida ou eliminada. Ao situar a noção em relação a uma situação particular, un peu restringe a determinação de uma

9 Todo pré-construto é um ponto fictício que se coloca como uma estabilidade provisória para determinações ulteriores. 
ocorrência atual de trabalhador aos sujeitos conhecidos dos interlocutores,

dentre os quais Pedro. Instanciada a base nominal do pré-construto por Pedro, observa-se que não se poderá chamar esse sujeito de "trabalhador" na situação atual. Com efeito, na retomada, o contexto encaixante joga a noção para a região de fronteira do domínio, onde é possível a formatação densa da representação. Un peu equilibra a instabilidade nocional e reorienta a projeção de existência de trabalhador do pré-construto. Para a obtenção do estado resultante do processo trabalhar, foi suficiente o tanto trabalhado por Pedro, ainda que se possa questionar se Pedro pode ser chamado de "trabalhador". Em suma, a instanciação da noção é discreta e a sua formatação é densa, em (2).

Toda ocorrência nocional, ao passar de uma representação cognitiva a uma representação linguística é situada em relação a um espaço de referência. Portanto, traz para esse espaço as projeções de sentido do pré-construto. De fato,

todo enunciado parte de uma noção inicial, com valor predicativo, ou causal, passa por um caminho aspecto-modal, que nada mais é do que a alteridade (seja animada, seja inanimada, seja o outro-outro, seja o outro-o mesmo) que oferece a espessura dialógica necessária para que a representação venha a ter existência conforme ela precisa ter existência (REZENDE, 2000, p. 148 [grifo nosso]).

A significação dos textos é um construto da atividade de linguagem. O sujeito está na gênese de todo o processo de construção de significação em situação prática, quer ratificando, quer reorientando as projeções de existência de representação que traz para o diálogo. Desse ponto de vista, as intenções argumentativas estão na origem do processo de construção de significação em língua. Na trajetória da representação, são observadas tendências (projeções de representação) que nem sempre estão disponíveis numa dada situação. O contexto encaixante explicita vestígios de operações sobre trajetórias nem sempre bem-sucedidas da instanciação de representações abstratas em representações referenciais que as situa em relação a sujeitos e temposespaços particulares.

\section{À guisa de uma conclusão}

Este texto trata do jogo de orientações que está fundamentado não só pelas intenções de significação de um dado sujeito, mas também pelas intenções da alteridade. A orientação é sempre o resultado do 
cumprimento das nossas intenções e, portanto, do jogo intersubjetivo subjacente à superfície dos enunciados. Em cada situação particular de diálogo, jogamos com a margem de deslocamentos, deformações, transformações, temporalidades, referenciais, forças, preponderâncias, e assim por diante, subjacentes aos valores e às significações das unidades de língua. Se, por um lado, a TAL optou por teorizar os valores que realçam na superfície do enunciado, por outro lado, a TOPE avança na teorização do espaço movediço de muitos resultados possíveis, dentre os quais, aqueles que ganham realce na cultura.

A TOPE não nega a suposição de que podemos orientar o enunciado de modo a determinar as opções do outro, como quer a TAL. No entanto, TOPE assume, diferentemente da TAL, que, se temos a intenção de orientar as opções do outro, temos de calibrar nossas representações com aquelas que acreditamos ser as do outro. Nesse sentido, entendemos que as duas teorias sejam convergentes, ainda que de modos diferentes, quanto ao acolhimento da alteridade nas análises.

Para a TAL, o jogo intersubjetivo é apreensível ao nível do sentido, que é interno à langue, através de encadeamentos argumentativos. Desse ponto de vista, assim como para Benveniste, entende-se por atividade de linguagem a prática de operacionalização da langue ("colocar em funcionamento a língua"). Através da submissão da langue às intenções de um sujeito, também se espera que a presença do outro se submeta ao seu controle no enunciado. A célebre afirmação de Fernando Pessoa, de que "a linguagem fez-se para que nos sirvamos dela, não para que a sirvamos a ela" (PESSOA, 1997, p. 73) talvez sumarize de modo contundente o projeto teórico da TAL.

A apreensão do jogo intersubjetivo pela TOPE está teorizada como a prática de construção de representação, referenciação e regulação. Desse ponto de vista, a significação não é o efeito do uso ou da operacionalização da langue. É o construto da atividade significante dos sujeitos. O sujeito é aquele que se antepõe, através de projeções de representação, e se sobrepõe, através de modulações sobre tais projeções, na situação particular de diálogo. De fato, "o sujeito encontra-se inscrito no próprio âmago da teoria" (FUCHS, 1984, p. 82). Desse ponto de vista, peu e un peu são mais do que marcas do homem na língua, são marcas do trabalho do sujeito para se fazer homem na língua. Do ponto de vista operatório, fazer-se homem implica equilibrar as assimetrias experienciais e linguísticas entre sujeitos. São constitutivas do enunciado as marcas desse trabalho. 
Se, para a TAL a alteridade é apreensível ao nível do sentido, na definição dos encadeamentos argumentativos, para a TOPE, é apreensível ao nível da atividade de linguagem e atravessa o processo de construção da significação. Nesse caso, o sujeito está na gênese de todas as opções e escolhas do processo constitutivo do enunciado. As projeções de representação que fundamentam o enunciado são apenas pontos provisórios de estabilidade dentro de um espaço fundamentalmente instável de valores e de opções.

A TAL é um projeto teórico assente em raciocínios polares ou excludentes, tais como a oposição entre o sucesso e o fracasso. Esse tipo de raciocínio oblitera a observação do movimento da representação para aquém ou para além de polos ou de valores observados como tais. Ficamos com valores polarizados, como se assim fosse desde sempre. Ficamos com a intuição de que a oposição empírica entre o sucesso e o fracasso, mas não só, e a experiência subjetiva, que possibilita sua apreensão no mundo, sejam sempre coincidentes. Em suma, a linguística que se desenvolveu na esteira do signo (SAUSSURE, 1971) desconhece os mecanismos perceptivos e a percepção é sempre a mesma para qualquer sujeito.

Através do conceito de aspecto, que articula forma (pontos de vista) e posição (padrões léxico-gramaticais) em situações práticas de diálogo, a TOPE consegue apreender o movimento da representação num vai-e-vem entre pontos fictícios (provisórios) de estabilidade e estabilizações singulares, munidas de propriedades referenciais que ancoram a experiência subjetiva em relação a sujeitos e tempos-espaços singulares. Com efeito, cada situação singular de diálogo é apreendida em toda a sua densidade experiencial e perceptiva pela teoria.

\section{Referências}

ANSCOMBRE, J. C.; DUCROT, O. L'Argumentation dans la langue. 2. ed. Bruxelles: Mardaga, 1988.

BENVENISTE, E. O aparelho formal da enunciação. In: BENVENISTE, E. Problemas de linguística geral II. Tradução de Eduardo Guimarães et al. 2. ed. Campinas: Pontes, 2006. Cap. 5, p. 81-90.

CULIOLI, A. Linguistique du discours et discours sur la linguistique. Revue philosophique, v. 4, p. 481-488, 1978.

Paris: Ophrys, 1990.

Pour unelinguistique del'énonciation: opérations et representations. 
Pour une linguistique de l'énonciation: formalisation et opérations de repérage. Paris: Ophrys, 1999 . Ophrys, $1999 \mathrm{~b}$

Pour une linguistique de l'énonciation: domaine notionnel. Paris: DUCROT, O. Les mots du discours. Paris: Minuit, 1980. 1987. o dizer e o dito. Tradução de Eduardo Guimarães. Campinas: Pontes,

FUCHS, C. O sujeito na teoria enunciativa de A. Culioli: algumas referências. Tradução de Letícia M. R. Robert. Caderno de Estudos Linguísticos, n. 7, p. $77-85,1984$.

PESSOA, F. A língua portuguesa. Lisboa: Assírio \& Alvim, 1997.

PRIA, A. D. O diálogo, a significação e a enunciação na articulação da linguagem com as línguas naturais. In: PRIA, A. D. et al. (Orgs.) Linguagem, escrita e tecnologia. Campinas: Pontes Editores, 2013. p. 37-50.

REZENDE, L. M. Léxico e gramática: aproximação de problemas linguísticos com educacionais. 2000. Tese (Livre docência) - Faculdade de Ciências e Letras, Universidade Estadual Paulista, Araraquara, 2000.

SAUSSURE, F. de. Cours de linguistique générale. Paris: Payot, 1971.

VOGÜE, S; PAILLARD, D. Modos de presença do outro. In: VOGÜE, S. et al. Linguagem e enunciação: representação, referenciação e regulação. Tradução de Márcia Romero e Milenne Biasotto-Holmo. São Paulo: Contexto, 2011. p. 131-159.

VOGÜE, S. Discret, Dense, Compact: Les enjeux énonciatifs d'une typologie lexicale. La notion de prédicat. Collection ERA-642, Université de Paris 7, p. $1-38,1989$.

Recebido em: 28 de jul. de 2017.

Aceito em: 09 de out. de 2017. 